\title{
ÍNDIA, UMA HISTÓRIA CRÍTICA
}

\author{
Carlos Alberto da Fonseca
}

RESUMO: Le discours historiographique sur l'Inde a subi à chaque pas de son élaboration les influences venues des présupposés idéologiques présents d'une manière ou de l'autre dans le cadre mental ou contextuel où vivait son auteur. C'est ainsi qu'on peut lire l'oeuvre historiographique de James Mill, Christian Lassen et Vincent Smith, du versant anglais, et les traces de Hegel dans leurs lignes; et encore l'ombre de la Grèce ancienne au centre même de l'interprétation de l'histoire de l'Inde faite par les historiens indiens écrivant au XX $X^{e}$ siècle tels que Jayaswal et Coomaraswami; et encore le recours à d'autres sources matérielles, au-delà de la littérature, comme les fouilles archéologiques et les documents numismatiques et epigraphiques etc. et même la méthodologie venue des sciences sociales. Au sommet de ce long mouvement, le petit livre de Romila Thapar, douée d'un nouvel regard.

PALAVRAS-CHAVE: História da Índia, Cultura indiana, Discurso historiográfico.

Por um lado, a bomba atômica, cujos segredos seguramente a Índia domina, e seus longos e higiênicos corredores de paredes tão espessas quanto o silêncio sobre o assunto; por outro, os problemas inerentes ao viver cotidiano, multiplicado por mais ou menos 800 milhões de vezes e remultiplicado por mais ou menos três mil outras vezes. Complexo país, complexa cultura, complexa gente. Complexa história* - no entanto reduzida, conforme o olho da época do observador, a algumas imagens por demais gastas.

Algumas não mais existem, como os Marajás, agora reduzidos a administradores dos hotéis em que se converteram seus luxos e seus palácios, a contar moedas e a servir refrescos perfumados aos hóspedes no jardim. Outras ainda persistem, como os mal-alimentados Encantadores de serpentes surdas e desdentadas que procuram seguir com os olhos os movimentos de alguma flauta que só pára de tocar quando uma moeda cai num pratinho de metal. Outras imagens, ainda, são criadas e realimentadas a cada passo na medida mesma em que o Ocidente não se entende e projeta como refúgio deslocado uma usina tão inesgotável quanto variada de práticas e crenças. Quantas histórias sedutoras, desde as gigantescas formigas que Heródoto não viu e que extraíam do solo enormes pepitas de ouro! Quanta sedução historiada, desde que o comerciante florentino Filippo Sassetti disse, no final do século XVI mas só revelado ao mundo na metade do século XIX, que (a palavra) Sânscrito queria dizer "bene articolato" porque seus falantes mascavam bétele! (MARCUCCI, 1855, p. 415)

Essa é uma história da Índia, feita dessas histórias sobre a Índia, e sempre foi feita, cada vez num momento, com os elementos mais aos olhos e à mão - a bomba, a miséria, os marajás, os encantadores de serpente, os yogas e os karmans, as formigas e todo o folclore sobre o Sânscrito. Mas existe uma outra história, que caminhou inextricavelmente tecida a essa e que, feita de matéria muito semelhante, diz respeito ao trabalho de gabinete - ou talvez se devesse dizer: que aos poucos foi saindo de uma torre de marfim. É a história dessa história que está aqui em pauta, a história de uma escrita histórica sobre a Índia que existe já há dois séculos, que exibe uma instrutiva série de mudanças de

Carlos Alberto da Fonseca é professor da Faculdade de Filosofia Letras e Ciências Humanas da USP.

* Conferência proferida na Faculdade de Letras da Universidade Federal de Minas Gerais, Belo Horizonte, MG, a 15.04.1993; e na VIII SEMANA DE ESTUDOS CLÁSSICOS, da Secretaria Regional SE-6 da Sociedade Brasileira de Estudos Clássicos, realizada na Faculdade de Ciências e Letras da UNESP, Araraquara, SP, no período de 10-14.05.1993. 
orientação e interpretação, que se faz apesar de alguns estereótipos que ela mesma cria.

A Índia, como se sabe, ou como aos poucos se redescobre, não foi uma cultura desconhecida e isolada. Existem numerosíssimas referências a ela desde antes e depois de Heródoto (para a comunicação entre a Índia e o Ocidente, ver JAROCKA, 1991) até o século XVIII. Existiram os missionários jesuítas e os mercadores, e também os embaixadores, como Sir Thomas Roe, que visitou (1615-1619) a corte mogol de Jahangir sob o reinado de James I, ou como François Bernier, da corte de Louis XIV, em 1668. Há portugueses (J. de Lucena e Diogo do Couto) e neerlandeses (A. Rogerius e Ph. Baldaeus), outros franceses e também ingleses nessa história, e também a viagem quase-épica de Anquetil-Duperron em busca de uma tradução persa do século XVII das UpaniLad sânscritas que valerão ouro para Schopenhauer. Tudo isso se converteu em relatos de viagem - a figura do "historiador" ou "intérprete da história” da Índia só vai surgir com a virada para o século XVIII em Calcutta.

Em Calcutta, esse primeiro momento da história da história da Índia começa com a fundação da Royal Asiatic Society (1784) e o trabalho que aí desempenharão os officers e os juízes britânicos empregados pela East India Company. Recebendo notícias de Londres, a Alemanha e o emergente Romantismo farão sua parte, que logo se espraiará pelas margens do Sena. De qualquer modo, a Índia será vista sempre segundo atitudes ideológicas dominantes na Europa em cada momento e, como seria de supor, significativamente diferentes da tradição indiana em si mesma e agravadas por questões ligadas à natureza dos informantes dos estudiosos. O certo é que esses trabalhos continuaram a ser influentes mesmo depois que os indianos começaram a estudar seu passado e a escrever sobre ele e, dado que freqüentemente escreviam para responder às interpretações feitas pelos ocidentais, foram por elas moldados.

Para mais bem administrar os territórios sob sua responsabilidade, os ingleses tiveram de se familiarizar com as leis, os costumes e a história dos indianos, e isso os levou a estudar os sistemas jurídicos indianos antigos. Isso os levou a estudar o Sânscrito, o que determinou o conhecimento e a divulgação da literatura sânscrita. Mas por que não os sistemas, os códigos, da época? Porque seus mestres e informantes eram brâmanes que, ciosos da presença e do domínio muçulmanos, quiseram dar ao administrador consentido provas intelectuais de um passado em que a intolerância religiosa ainda não se instalara, em que o confronto de raças ainda não dividia o povo, em que o Sânscrito era o registro lingüístico culto único. Guardiães da tradição indiana clássica antiga, esses brâmanes passaram aos britânicos residentes a visão de mundo que a casta bramânica formulou na Índia antiga sobre a Índia antiga, os textos que, de natureza religiosa em boa parte, emanaram do passado de um segmento particular da sociedade indiana e a ele diziam respeito. Este fato passou absolutamente desapercebido - e muitos dos preconceitos ideológicos contemporâneos dos pandits e suas releituras dos textos antigos foram freqüentemente incorporados naquilo que se acreditava fosse uma interpretação confiável. Além disso, não se percebeu também que "ser entendido em assuntos de religião" não torna ninguém um "sacerdote" e que o dharma, a "forma de viver", inclui a religião apenas como um de seus componentes. Isso viciou o estudo da cultura antiga, particularmente no que dizia respeito à literatura jurídica. Mas viciou também o conhecimento da cultura contemporânea, sobre a qual se projetaram as sombras fortes do imutável, do estático, do idílico. Chega-se até a organizar um Digesto da Lei Hindu sobre Contratos e Sucessões (1797-1798) baseado no Código de Manu, de séculos a.C. - forçando-se uma formulação jurídica que não se adequava mais à realidade já fazia muito tempo.

Assim, se, na visão dos brâmanes, tudo sempre foi paz antes dos muçulmanos, ou foi rápida e eficazmente resolvido, as primeiras "histórias de administrador" da Índia trataram de ressaltar nessa passagem tranquila pelo tempo algumas ilhas relevantes, diferentemente das histórias da Europa que se elaboravam no século XIX e que ressaltavam diferentes modelos de evolução surgidos e tentados no rastro da Revolução Francesa. Essas ilhas soltas no tempo - reis de dinastias fortes e impérios sólidos terminaram por construir a imagem corrente do governante indiano antigo como autocrático e opressor, nada preocupado com o bem-estar dos súditos. Nessa história, Açoka (século V a.C.), Candragupta II (século IV d.C.) e Akbar (século XVI) são exceção, mas a administração britânica que aí se lê no contraplano era muito superior.

Em resumo: administradores e juízes querem conhecer o presente, recorrem a informantes privilegiados que lhes interpretam enviesadamente o passado, que é projetado no presente para uma oposição mais forte a um inimigo interno comum.

Às vezes com intenções derivadas. É assim que, por exemplo, a History of British India, de James Mill, de 1817, divide a história da Índia em três períodos: a) civilização hindu, chamada depois de "antiga", que teria começado com a chegada dos Trya ao vale do Indo e terminado no século XI d.C. 
com as primeiras incursões turcas no Norte; b) na continuação, a civilização muçulmana, ou "medieval", que alcançaria a chegada dos ingleses em meados do século XIX; e c) período britânico, ou "moderno". O primeiro período teria sido "integrador"; o segundo, "separatista" - e talvez se pudesse inferir, sem muito esforço, que o terceiro fosse "redentor".

Essa visão tomava a religião como o fator que motivava as mudanças na história indiana, como os rótulos implicam. Ocorre que ela era apenas um dentre vários fatores e, no que é chamado de hindu, existem diferenças flagrantes entre a religião do período védico, do período bramânico e do período clássico (ou bramânico renovado), como querem os rótulos de outra tradição.

Para Mill, a sociedade indiana continuou substancialmente a mesma, estática e sem mudanças, desde sua origem até a chegada dos britânicos; nunca demonstrou ela grande interesse pelos valores políticos, pois os indianos foram governados por uma série de déspotas e tiranos até a chegada dos britânicos, que levaram para a Índia o principal valor de uma cultura, qual seja, um grau elevado de manutenção do racionalismo. Além disso, Mill acreditava firmemente no princípio utilitarista de que a legislação pode desenvolver uma sociedade - em vez de ela representar o ideal social para e num determinado momento. No contexto indiano, a crença de Mill implicava que os administradores britânicos, ao aplicarem uma legislação previamente estabelecida, poderiam mudar a Índia de uma sociedade tradicional, imutável, numa sociedade progressista e dinâmica, dentro dos termos utilitaristas. Não preocupava Mill, ao menos minimamente, que a nova legislação não tivesse raízes no sistema social indiano e nem que as bases das mudanças devessem ser pensadas de modo mais abrangente.

A afirmação de Mill de que o passado indiano foi o de uma sociedade sem mudanças, estática, dominada por governantes despóticos, vai-se refletir em várias filosofias da história, dentre as quais as de Hegel (1837), e dar legitimidade intelectual à teoria do Despotismo Oriental. Esta não era uma idéia nova: há traços dela em Heródoto (antagonismo Grécia-Pérsia) e Aristóteles (natureza da realeza e os sistemas políticos da Ásia), mas foi retomada e desenvolvida como teoria política no Esprit des Lois de Montesquieu e debatida por Voltaire. Quanto à Índia, a teoria do Despotismo Oriental se assentava na afirmação - errônea, como hoje se sabe - de que não existia propriedade privada da terra na Índia pré-histórica, crença baseada na incompreensão do sistema agrário do império mogol por parte dos já referidos Thomas Roe e François Bernier.

Interessa aqui, falando de historiadores, que a dialética de Hegel foi aplicada por Christian Lassen (meados do século XIX) à periodização da história da Índia: à tese corresponde o "período hindu"; à antítese, o "período muçulmano" e, à síntese, um certo "período cristão". Tentando, deste modo, conectar a história indiana à corrente geral da história do mundo no palco comum da civilização cristã, Lassen fortaleceu a periodização de Mill e reafirmou a avaliação de Hegel sobre a natureza imutável do passado indiano. Isso tudo vai dar na tese de Karl Marx sobre o Modo de Produção Asiático, baseada principalmente no estudo da aldeia indiana como unidade produtiva e explorada pelo Estado, que dela extraía a máxima porcentagem do excesso mínimo de produção para possibilitar ao déspota viver em luxo considerável. Como nas aldeias existiam castas, e estas estavam estabelecidas desde os tempos mais remotos, esse Modo de Produção era a prova definitiva da imutabilidade da Índia em todos os aspectos.

Outro tipo de entusiasmo: em 1791, Thomas Jefferson conheceu William Jones em Paris e dele ganhou um exemplar de sua tradução da peça AbhijñTnaçakuntalT de KTlidTsa e o enviou, singrando as águas do Atlântico, à sua filha nos recentes Estados Unidos para introduzi-la na literatura clássica. Não se sabe qual foi o proveito que a mocinha tirou desse presente, mas essa mesma ÇakuntalT foi, por outros caminhos, parar nas mãos de Goethe e de muitas outras pessoas na Alemanha do começo do século XIX e conquistou a admiração dos poetas do movimento romântico. Na França ela fez furor em 1830 (tradução de Leonard de Chézy), em 1850 (adaptação de Théophile Gautier para balé), no começo do século XX (coreografia de Balanchine - La Bayadère, que foi também o último balé dirigido por Nureyev em 1992). Embora a Société Asiatique, fundada em Paris em 1822, levasse mais a sério essa questão do conhecimento da Índia, porque nenhum de seus membros escrevia à sombra de deveres administrativos e política governamental, não demorou que pelos boulevards e pela literatura de primeiro, segundo e terceiro escalões surgissem tantas Índias quantas fossem necessárias para suprir as carências geradas pelo furacão de 1789. A "metafísica" e as sutilezas estranhas mas benvindas da crença religiosa dos indianos, que nunca tinham tido tempo para atividades mundanas, segundo esse recorte, se transformaram nas virtudes exigidas para a busca de uma distante Utopia para se escapar das mudanças desorientadoras da Europa do século XIX. O presente indiano (mistura de muçulmano com hindu) era, em sua materialidade, muçulmano e, em sua espiritualidade, hindu - uma síntese que até hoje a própria 
Índia não conseguiu, e tentativas disso sempre foram infrutíferas. Imutável, desde sempre igual, na sociedade indiana recortava-se a aldeia como centro idílico da vida e o pano de fundo natural para as qualidades de moderação, sinceridade e ascetismo. A Índia passou a ser, então, para muitos europeus, a terra mística onde até os atos mais ordinários da vida estavam imbuídos de simbolismo - para o que concorreu também La Chaumière indienne, de Bernardin de Saint-Pierre, cujo pária será o modelo de todos os párias românticos. A Índia era a gênese de tudo e também o refúgio dos intelectuais europeus que buscavam escapar de seu próprio sistema de vida. Afirmou-se uma dicotomia de valores: os indianos foram definidos como "espiritualistas" e os europeus como "materialistas", sem que se tentasse situar esses valores supostamente espirituais em seus devidos contextos na sociedade indiana de cada tempo: os aspectos sociais e políticos do Budismo ficaram inobservados até o século XX, dos materialistas indianos ainda muito pouco se fala - e teriam sido muito grandes as surpresas. Como nessa história toda ninguém é inocente, esse tema da oposição entre "espiritualismo indiano" e "materialismo europeu/ocidental" caiu nas penas de alguns pensadores indianos durante os últimos cem anos e para eles foi um consolo terem recebido dos europeus uma arma com que competir com a alegada superioridade técnica, política e cultural da Inglaterra - e o merchandising e o marketing dessas idéias continuam rendendo até hoje.

Conforme a expressão da historiadora Romila Thapar, houve ainda outra bête noire - le miracle grec. Dado que, por um lado, a Índia preenchia o irracional e, por outro, a educação desses historiadores, feita segundo os modelos e conteúdos da tradição clássica, forrava o racional, toda e qualquer cultura não-européia era medida com a Grécia antiga, num confronto do qual saía invariavelmente plena de lacunas e deficiências. Se, por acaso, ela apresentava alguns traços individuais dignos de admiração, tendia-se a relacioná-los de algum ou qualquer modo à cultura grega.

Foi o que aconteceu com a Early History of India, de Vincent Smith, de 1904. Seu viés pró-cultura grega levou-o a assim interpretar uma pintura que integra os murais do famoso santuário budista de AjantT, que, segundo se supunha, representava a chegada de uma embaixada enviada por um rei sassânida da Pérsia do século VII d.C. - pintura que nada tinha a ver com a Grécia nem do ponto de vista histórico nem do ponto de vista artístico:

O quadro, além de seu interesse como registro contemporâneo de relações políticas inusitadas entre Índia e Pérsia, tem um valor máximo como marco na história da arte. Não só fixa a data de algumas das pinturas mais importantes de AjantT, e assim estabelece uma norma pela qual julgar a data de outras, mas também sugere a possibilidade de que a escola de arte pictórica de AjantT derivou da Pérsia e, em última instância, da Grécia. (apud THAPAR, 1969a , p. 15)

É nesse contexto que se deve ler também A Literatura da Índia Antiga, de Hermann Oldenberg, para quem o MahTbhTrata, diferentemente das epopéias gregas,

é uma epopéia exagerada, rica, informe e confusa, expressão exata do espírito hindu [= indiano]. Como o exige a Índia, o verdadeiro heroísmo foi substituído pela exaltação de feitos de força e valentia sobre-humanos, inventados por débeis. Independentemente da ação principal se desenvolve um intricado emaranhado de episódios, fábulas, sistemas de filosofia e direito, a obra inteira semelhante à jângal impenetrável, cujas árvores ultrapassam a exuberância das trepadeiras e se unem numa cúpula multicolorida. (OLDENBERG, 1956, p. 10)

Estivesse Oldenberg absolutamente convicto de que a estrutura do MahTbhTrata termina por homologar textualmente o ambiente em que foi produzida, tudo o que diz seriam elogios. Mas para ele só existem defeitos, como os apontados nesta outra passagem:

Muitos dos traços em que contrastam o pensador hindu e o do Antigo Testamento se assemelham, por outro lado, aos do grego com que já o comparamos e cujo nome já mencionamos antes: Parmênides, o autor do poema moral sobre a unidade e a imortalidade do Ser Eterno. Acredita-se sentir a diferença entre a raça ária e a semita; frente à riqueza de imagens, de cores brilhantes e da agilidade apaixonada do hebreu, encontra-se na Índia, como na Grécia, a mesma inclinação para o abstrato e o mesmo tom impessoal de serena alegria pelo saber. Na poesia do hindu, como na do grego, estão em primeiro lugar as duas mesmas abstrações: ser, ou não ser, que serão empregadas como chave para solucionar os mais profundos mistérios. Mas com que distinta segurança sabe mover-se Parmênides nessas regiões. Em todo lugar encontramos pensamentos firmes bem construídos, cada um em seu lugar. Sempre se procura comprovar, demonstrar que nenhum outro conceito é admissível no lugar do seu. Por toda parte encontramos a palavra "pois". Hoje em dia podemos negar fé a essas provas, podemos ter compreendido que é um privilégio da juventude considerar que até mesmo as maiores alturas são acessíveis à sua ousadia. Mas devemos reconhecer que essa juventude de espírito com seu vigor sadio poderá se desenvolver até a virilidade. E se contemplamos sob esse ponto de vista a poesia védica, teremos a sensação de nos termos extraviado, indo do país das 
formas fixas para uma região povoada de nuvens informes. Em toda parte encontramos afirmações e negações ilimitadas, massas sem contornos que se elevam de entre as névoas para logo desaparecer. Foi o precoce espírito popular que no passado na Índia védica soube conjurar tais fenômenos. Crescerá algum dia até a plenitude do vigor viril, ou já existe em germe nesta adolescência da cultura hindu o estigma do rápido esgotamento de toda força vital que significa uma decadência prematura? (OLDENBERG, 1956, pp. 61-62)

É então que começam a ser ouvidas as vozes indianas. Houve uma primeira geração de historiadores indianos da Índia antiga muito pouco expressiva na virada para o século XX, de origem bramânica e sem perspectiva própria que não fosse a de seguir os modelos britânicos da história dinástica e política. R. G. Bhandarkar, um dos representantes desse primeiro momento, estava consciente dos preconceitos óbvios dos historiadores contemporâneos, mas o pano de fundo cultural no qual se movimentava tendia a inibir um estudo crítico ou analítico das fontes a que recorria - até o momento, apenas a literatura sânscrita, a da elite cultural dominante em toda a Índia antiga. Nesse sentido, seus estudos lingüísticos são muito mais interessantes e legíveis que seus estudos históricos: até parece querer dizer com isso que tocar, mesmo fundo, em questões de linguagem não implica tocar, mesmo de leve, em questões sociais.

A segunda geração, dos anos 20 e 30 do século XX, reagiu vivamente. Mas, ao radicalizar sua posição, cometeu erros estratégicos que reperturbaram o conhecimento da história da Índia. Todos os integrantes desse momento estiveram engajados no movimento nacionalista, que terminou por levar à independência, ou foram por ele influenciada. Continuaram a escrever história política e dinástica, mas suas interpretações se faziam no sentido de reagir à visão já velha de um século de Mill, reação entendida como um passo necessário para a afirmação do auto-respeito nacional, o que se conseguiria, segundo eles, com a glorificação sem amarras de um passado glorioso, visto como compensação para as agruras de um presente humilhante.

Começaram por tentar demonstrar que a Índia nada devia à Grécia, que a cultura indiana constituía um paralelo próximo à Grécia mas com ela não se confundia, que ela manifestava por criação própria muitas das qualidades presentes na cultura grega. Longe de reconhecerem que cada civilização é seu próprio milagre, enfileiraram todos os elogios que no século XIX foram feitos à indianidade da cultura indiana com um resgate e uma glorificação de todos os orientalistas simpáticos à Índia, dentre os quais adquirem relevo os elogios de Max Muller, a todo momento citado.

Assim, K. P. Jayaswal afirma que a vida política das repúblicas indianas antigas baseava-se nos conceitos gregos de democracia e governo representativo no mesmo grau que a vida política das cidades-Estado gregas - o que parece ter força suficiente para colocar o Despotismo Oriental bem longe das preocupações dos historiadores. Para A. K. Coomaraswami, a superioridade estética grega estava em cheque: se os artistas gregos eram famosos pelo trabalho e pela fixação da beleza física, o que os indianos procuravam era a expressão de valores espirituais elevados: se à Índia faltavam o racional e o pragmático, era necessário afirmar que a cultura indiana era essencialmente espiritualista, oposta à civilização ocidental materialista, e por isso era superior a ela.

Como os dezenovistas haviam estabelecido que a Índia não havia mudado de 1.000 a.C. até 1.000 d.C. e que a base dessa estabilidade havia sido a cultura ária, tendo eles sugerido, ao apequenarem as consecuções indianas, que elas foram emprestadas da Grécia, esses historiadores começaram a colocar suas fontes literárias, ainda suas únicas fontes, tão recuadas no passado de modo que lhes fosse possível provar que os aspectos que valia a pena resgatar como indianos eram total e completamente indianos. Isso acabou, por um lado, por fazer a história começar antes da chegada dos árias, antes da chegada do componente indo-europeu (e, como tal, grego) à cultura dravídica que, nessa altura, ninguém mais poderia negar: a arqueologia já escancarara para os céus as ruínas de Mohenjo-Daro e Harappa, cidades do vale do Indo anteriores à chegada dos indo-europeus. A incorporação dessa revelação foi importante: aos poucos o elogio do passado vai-se convertendo em mero registro de fatos e abrindo caminho para uma visão menos apaixonada mas mais responsável. Começam a ser feitas algumas perguntas destoantes com relação ao passado dessa escrita histórica: o que possibilitou que o império Maurya, por exemplo, fosse relevante, para além da unidade política conseguida por Açoka e seu status de governante?

Perguntas desse tipo, porém, foram poucas, e tímidas. O que prevaleceu foi o olhar sobre o Norte do país, a bacia gangética, fortemente influenciada pela cultura ária do vale do Indo, e aproximações entre modelos gregos e ocidentais, num outro nível: Maquiavel e Bismarck estavam prefigurados no ArthaçTstra, tratado de economia do século II a.C., elaborado por KauFilya, cujo monarca era em tudo semelhante ao monarca constitucional dos ingleses; por outro lado, se a assembléia 
de ministros dos governantes indianos, a mantrapariLad, se assemelhava ao Privy Council of Britain, o marajá Samudragupta, do século IV d.C., era comparado nada menos que a Napoleão... enquanto KTlidTsa, o maior dos dramaturgos/literatos indianos clássicos era igualado, numa outra série discursiva mas com o mesmo espírito, a Virgílio, Teócrito, Shakespeare e Théophile Gautier (HENRY, 1904, p. 217).

À medida que a movimentação pela independência crescia e tornava cada vez mais evidente a separação da Índia em dois países, crescia também a animosidade bíblio-histórica. O nacionalismo foi tomando tinturas de uma forma de Hinduísmo militante e as causas de muitos dos males da Índia tinha nome e cara: as invasões e o governo muçulmanos. Nessa revisão mais radical, o período Gupta, até então encravado na "história antiga", tornou-se a Era de Ouro da Índia - porque foi o período de engendramento do Hinduísmo. Na seqüência, foi ela considerada a cultura essencial da Índia: quaisquer outras forças culturais foram tidas como intrusão, disso não escapando nem mesmo o próprio Budismo: ser heterodoxo se transforma também em heterotópico. Paralelamente, reconhece-se o imperialismo indiano sobre muitas culturas asiáticas como forma de afirmação nacional: do mesmo modo que o Islã foi chegando à Índia desde o século VII d.C., também o Hinduísmo foi-se expandindo pelos oceanos Índico e Pacífico afora.

Após a independência, a escrita histórica, além de ter-se avermelhado, começou a buscar outras fontes. As correntes nacionalistas haviam lançado raízes fortes e profundas. Agora, a investigação histórica, sem abandonar as fontes literárias, passa a ler também os documentos arqueológicos, numismáticos, etnológicos, epigráficos etc.; além disso, deixa de ser atividade exercida por pessoas vagamente rotuladas de "orientalistas" e se inclina decididamente para a metodologia e as estratégias das ciências sociais, o que resulta em programas de investigação completamente diferentes. Por um lado, reconhece-se como fio condutor a idéia de que mudanças no sistema político estão inextricavelmente entretecidas com mudanças na estrutura econômica, que, por sua vez, influenciam as relações sociais; que, se um movimento religioso, por exemplo, se arraiga, então a atração que ele exerce deve guardar uma relação com o lugar social dos que o apoiam; que, se um dialeto adquire foros de língua e se uma literatura se formaliza nessa língua, então algo profundamente significativo aconteceu não só lingüística e literariamente com os falantes dessa língua. Por outro lado, surge e cresce um interesse pela elaboração de histórias locais e regionais, que corrigem a tendência à generalização para todo o subcontinente das bases culturais do vale do Ganges e da ideologia bramânica - interesse que leva à descoberta de novas fontes em arquivos locais e a um trabalho arqueológico mais intenso, que levam à constatação de que existem variações regionais e históricas do padrão cultural e de que a mudança histórica não precisa ser nem idêntica nem simultânea.

Tendo-se iniciado meio marginalmente, essa corrente terminou por se estabelecer solidamente, principalmente no Sul da Índia e nos grandes centros de estudo do Norte, com uma compreensão serenada dos princípios do materialismo histórico e da filosofia da história de Marx procurando dar a essa concepção a história que ela negava à Índia. O estudo sistemático das relações entre a organização social, política e econômica e seus efeitos sobre os eventos históricos levou ao estabelecimento de relações de causa e efeito entre esses elementos e ao desenvolvimento da idéia de que é a inter-relação de uma variedade de forças que determina os eventos, cuja chave é os meios de produção.

Nesse sentido, não são mais significativas a história dinástica, a teoria do Despotismo Oriental, a tese do Modo Asiático de Produção: sabe-se, com o auxílio das novas fontes de informação, que existiu propriedade particular da terra e que seu gerenciamento mudou significativamente ao longo dos séculos. Não só as idéias são estudadas, mas também as práticas a elas associadas - como e por qual razão foram criadas, aceitas, recusadas ou modificadas; não só os períodos de mudança, mas também a natureza dessa mudança - bem como a natureza das relações sociais na estrutura da sociedade indiana antiga. Nesse sentido, crescem o número e a qualidade de estudos monográficos sobre aspectos particulares da cultura indiana: a criança, a educação, as castas, o comércio, a agricultura, o arrendamento da terra, o sistema de irrigação, os impostos, a condição feminina, a diferença lingüística, a diferença religiosa na pluralidade que é o Hinduísmo, etc. É muito rara, por exemplo, a publicação de uma obra de caráter mais abrangente: essa síntese está adiada enquanto se re/definem métodos e resultados.

Com relação à periodização da história da Índia, por exemplo, não se fala mais em três períodos. A tripartição Hindu/Muçulmano/Britânico - ou quaisquer dos outros termos -, elaborada pelas correntes dezenovistas, privilegiava indevidamente dinastias e invasões estrangeiras e se baseava no Norte da Índia: só as dinastias mudavam, não as características histórico-sociais. Esse modelo, segundo os historiadores contemporâneos, não pode ser aplicado a todo o subcontinente indiano. No que diz 
respeito à chegada dos muçulmanos - que dava início ao segundo período -, eles eram diferentes entre si e conquistaram partes diferentes da Índia em períodos diferentes: os árabes começaram a chegar ao Sind (Oeste) no século VIII d.C.; os turcos e os afegãos, no Panjab (Noroeste), no século X; os persas chegaram ao Norte no século XIII e alcançaram o Decão (Sul) no século XIV. O resultado mais significativo desse trabalho é a compreensão de que fases, bem definidas que sejam, de desenvolvimento histórico não se aplicam uniformemente à história de toda a sociedade.

Nesse particular, uma das primeiras súmulas, ainda perfeitamente legíveis e inspiradoras, de uma história geral da Índia antiga foi a History of India (1966) de Romila Thapar - um livro que "não foi escrito para o especialista em história da Índia" (THAPAR, 1969 a , p. 9), fato que, nesse contexto, e para além do cuidado de suas afirmações e seus desenvolvimentos, fica sendo uma das suas maiores qualidades. Começa com um segundo capítulo denominado "O enxerto da cultura ária" - a metáfora da planta não vai ser seguida no restante da obra, mas serve para tornar definitiva a idéia de que algo, a cultura dravídica, cujos traços vão sendo cada vez mais recuperados nos desenvolvimentos posteriores, já florescia no vale do Indo quando os indo-europeus ali chegaram. No terceiro capítulo, "Repúblicas e Reinos", 600-321 a.C., observa-se a convivência entre essas duas formas de governo em uma miríade de Estados pequenos e independentes cuja população exercitava na prática as abstrações principais que as UpaniLad e os códigos de leis discutiam: Ttman (o individual), brahman (o coletivo), karman (a ação individual) e dharma (o formato social) não eram os esoterismos em que os séculos XIX e XX os transformaram com sua ligação estreita ao VedTnta: todos eles dizem respeito ao complicado que é o viver cotidiano. No quarto capítulo, "O aparecimento do império", 321-185 a.C., estudam-se as condições que possibilitaram o surgimento e a ascenção dos Maurya, análise que termina no capítulo V, "A desintegração do império", 200 a.C.-300 d.C., que inclui um estudo da impossibilidade de manutenção do poder por parte dos kLatriya. O sexto capítulo, "Surgimento da comunidade mercantil", 200 a.C.-300 d.C., como que espelha essa resposta: o império kLatriya como que se inviabiliza diante do mercantilismo vaiçya. No sétimo capítulo, "Evolução do modelo 'clássico"”, 300-700, vê-se um relacionamento diferente entre os brThmaJa, agora recolhidos ao seu lugar filosófico e religioso, e as duas outras castas já referidas - segundo alguns, uma "burguesia emergente" -, responsáveis pelo financiamento do "clássico". Enquanto isso, entre 500 e 900, começam os "Conflitos nos reinos meridionais", capítulo oitavo, que acontecem sobretudo por causa das tentativas de domínio do Sul, dravídico, por parte do Norte e sua conseqüente e desejada "arianização", como se diz no inglês dos historiadores indianos. A seguir, capítulo nono, a "Ascenção do Sul”, 900-1300, mais como fixação de suas tradições próprias. Enquanto isso o Norte, rechaçado, parece se voltar para a compreensão de suas diferenças internas: é disso que trata o décimo capítulo, "Princípios dos estados regionais na Índia setentrional", 700-1200. Mais ou menos no mesmo período, 800-1200, configura-se o "Feudalismo nos estados regionais", capítulo onze. Nos dois capítulos seguintes, que abrangem o período 1200-1526, estão o "Realinhamento dos reinos regionais" e a "Prova de assimilação", que historiam as influências e as modificações ocorridas no Norte após a chegada dos muçulmanos. No último capítulo narra-se o "Ajuste no Sul", 1300-1526. Thapar não especifica a que se refere precisamente o ano de 1526, mas com toda certeza diz respeito ao ano em que, a 21 de abril, termina o Sultanato de Delhi, fato que trará modificações consideráveis à história da Índia - mas disto trata Percival Spear no volume II do mesmo título.

Como que resumindo suas preocupações, que também são nossas, Romila Thapar como que pede desculpas por assim julgar dever ser vista sua história do passado do seu país:

A finalidade de indicar o enfoque mutável da bibligrafia histórica sobre a Índia não é desfazer o trabalho dos primeiros historiadores, negando-lhes sua validade, nem negar a profundidade de seus conhecimentos. Os erros de sua interpretação foram com frequiência os erros próprios de sua época, porque um historiador amiúde é mais representativo do seu tempo do que ele pensa. Apesar de suas deficiências, esses estudos assentaram as bases da história da Índia e edificaram uma estrutura cronológica firme, sobre a qual se podem construir novas interpretações, que colocarão as idéias e as instituições da civilização indiana em sua perspectiva adequada. (THAPAR, $1969^{\mathrm{a}}$, p. 20)

Entre as paralelas em que ainda se movia, Romila Thapar já se afasta do mar, mas a sensação de sal nos pés ainda a faz sentir aqui e ali o frio da água. E isso sempre traz problemas e, na falta de um esclarecimento em orelhas do livro que fosse, sobre a vertente historiográfica em que o historiador se situa, no mínimo causa temor verificar que se continua oferecendo, não como obra ultrapassada, mas como material ainda válido, em reedições recentes, as histórias de Mill e Vincent; ou que, na sedução 
metafórica atemporalizadora que parece reger a leitura atual do mundo, alguém possa concordar com Shyamala Gupta, uma historiadora e crítica impressionada da arte indiana, que, no livro The Beautiful in Indian Arts, considera que

O homem védico morreu há milhares de anos. Nenhum dos artefatos que produziu chegou aos nossos dias. Mas ele ainda vive entre nós por meio da literatura que criou - the beautiful cream of language. Na Índia, progredimos com o passar do tempo, transformando-nos em pessoas sofisticadas que não vivem mais em casas cobertas de folhas de palmeiras! Vivemos em ambientes proporcionados pelo progresso tecnológico do século XX - as casas e os apartamentos com ar condicionado, os aviões e os carros, inumeráveis máquinas à nossa disposição para qualquer função. Já chegamos à lua e a conhecemos melhor. Começamos nossos dias com os hinos rigvédicos que eram cantados pelo homem védico há três mil anos. Nossa linguagem para expressar nossa relação com o sol, a lua, a monção, o fogo, o dia, a noite e toda a natureza é ainda a mesma linguagem que o homem védico cunhou! (GUPTA, 1979, p. 78)

O trem da velha história parece não parar em todas as estações. Mas já existem romancistas que o estão tirando dos trilhos: leia-se Salman Rushdie, V. S. Naipaul, Arundhati Roy, Shashi Tharoor, etc.

\section{BIBLIOGRAFIA}

GUPTA, Shyamala. The beautiful in indian arts. Delhi, Munshiram Manoharlal, 1979.

HENRY, Victor. Les littératures de l'Inde. Paris, Hachette, 1904.

JAROCKA, Marja Ludwika. La comunicación entre la India y Occidente antes y después de Alejandro.

BhTrata Cadernos de Cultura Indiana, São Paulo, no 3, pp. 31-57, 1991.

MARCUCCI, Ettore. Lettere edite e inedite di Filippo Sassetti. Firenze, Felice Le Monnier, 1855.

OLDENBERG, Hermann. La literatura de la antigua India. Buenos Aires, Losada, 1956.

THAPAR, Romila. Interpretation of ancient indian history. Journal of the Varendra Research Institute, Varanasi, $\mathrm{n}^{\circ}$ 2, pp. 1-25, 1973.

----- History of India, vol. I. México, Fondo de Cultura Económica, $1969^{\mathrm{a}}$.

----- Presidential address to the Indian history congress, Thirty-first Session. Varanasi, 1969 